\title{
The effects of "Fangcang, Huoshenshan, and Leishenshan" Hospitals and environmental factors on the mortality of COVID-19
}

\author{
Yuwen Cai $^{1,2}$, Tianlun Huang ${ }^{1}$, Xin Liu $^{1}{ }^{1}$, Gaosi Xu ${ }^{\text {Corresp. } 1}$ \\ ${ }^{1}$ Department of Nephrology, the Second Affiliated Hospital of Nanchang University, Nanchang University, Nanchang, China \\ 2 Second Clinical Medical College of Nanchang University, Nanchang, China \\ Corresponding Author: Gaosi Xu \\ Email address: c13879428390@163.com
}

Background. In December 2019, a novel coronavirus disease (COVID-19) broke out in Wuhan, China; however, the factors affecting the mortality of COVID-19 remain unclear.

Methods. Thirty-two days of data (the growth rate/mortality of COVID-19 cases) that were shared by Chinese National Health Commission and Chinese Weather Net were collected by two authors independently. Student's t-test or Mann-Whitney $U$ test was used to test the difference in the mortality of confirmed/severe cases before and after the use of "Fangcang, Huoshenshan, and Leishenshan" makeshift hospitals (MSHs). We also studied whether the above outcomes of COVID-19 cases were related to air temperature $(A T)$, relative humidity $(\mathrm{RH})$, or air quality index (AQI) by performing Pearson's analysis or Spearman's analysis.

Results. Eight days after the use of MSHs, the mortality of confirmed cases was significantly decreased both in Wuhan ( $t=4.5, P<0.001)$ and Hubei $(U=0, P<0.001)$, ( $t$ and $U$ are the test statistic used to test the significance of the difference). In contrast, the mortality of confirmed cases remained unchanged in non-Hubei regions $(U=76, P=0.106)$. While on day 12 and day 16 after the use of MSHs, the reduce in mortality was still significant both in Wuhan and Hubei; but in non-Hubei regions, the reduce also became significant this time $(U=123, P=0.036 ; U=171, P=0.015$, respectively). Mortality of confirmed cases was found to be negatively correlated with AT both in Wuhan $(r=-0.441, P=0.012)$ and Hubei $(r=-0.440, P=0.012)$. And both the growth rate and the mortality of COVID-19 cases were found to be significantly correlated with AQI in Wuhan and Hubei. However, no significant correlation between $\mathrm{RH}$ and the growth rate/mortality of COVID-19 cases was found in our study.

Conclusions. Our findings indicated that both the use of MSHs, the rise of AT, and the improvement of air quality were beneficial to the survival of COVID-19 patients. 


\section{The effects of "Fangcang, Huoshenshan, and}

2 Leishenshan" Hospitals and environmental factors on

3 the mortality of COVID-19

4

5 Yuwen Cai ${ }^{\text {ab }}$, Tianlun Huang ${ }^{\mathrm{a}}$, Xin Liu ${ }^{\mathrm{a}}$, Gaosi Xu ${ }^{\mathrm{a}^{*}}$ 7

\section{Abstract} or Spearman's analysis.

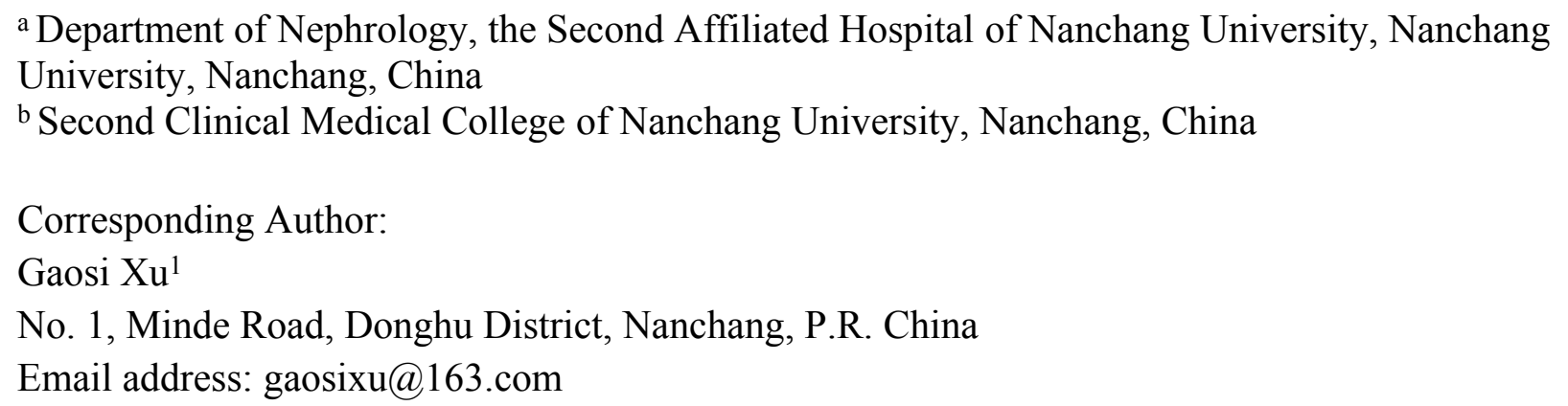

Background. In December 2019, a novel coronavirus disease (COVID-19) broke out in Wuhan, China; however, the factors affecting the mortality of COVID-19 remain unclear. Methods. Thirty-two days of data (the growth rate/mortality of COVID-19 cases) that were shared by Chinese National Health Commission and Chinese Weather Net were collected by two authors independently. Student's t-test or Mann-Whitney U test was used to test the difference in the mortality of confirmed/severe cases before and after the use of "Fangcang, Huoshenshan, and Leishenshan" makeshift hospitals (MSHs). We also studied whether the above outcomes of COVID-19 cases were related to air temperature (AT), relative humidity $(\mathrm{RH})$, or air quality index (AQI) by performing Pearson's analysis

Results. Eight days after the use of MSHs, the mortality of confirmed cases was significantly decreased both in Wuhan $(\mathrm{t}=4.5, P<0.001)$ and Hubei $(U=0, P<0.001)$, (t and $U$ are the test statistic used to test the significance of the difference). In contrast, 
30 the mortality of confirmed cases remained unchanged in non-Hubei regions $(U=76, P=$

31 0.106). While on day 12 and day 16 after the use of MSHs, the reduce in mortality was

32 still significant both in Wuhan and Hubei; but in non-Hubei regions, the reduce also 33 became significant this time $(U=123, P=0.036 ; U=171, P=0.015$, respectively $)$.

34 Mortality of confirmed cases was found to be negatively correlated with AT both in Wuhan $35(r=-0.441, P=0.012)$ and Hubei $(r=-0.440, P=0.012)$. And both the growth rate and 36 the mortality of COVID-19 cases were found to be significantly correlated with AQI in Wuhan and Hubei. However, no significant correlation between $\mathrm{RH}$ and the growth rate/mortality of COVID-19 cases was found in our study.

Conclusions. Our findings indicated that both the use of MSHs, the rise of AT, and the improvement of air quality were beneficial to the survival of COVID-19 patients.

\section{Introduction}

In early December 2019, a novel coronavirus disease (COVID-19), previously known as

2019-nCoV) induced by severe acute respiratory syndrome coronavirus 2 (SARS-CoV-2)

broke out in Wuhan, China $(1,2)$. This newly discovered coronavirus has been confirmed

to have human-to-human transmissibility (3) and has now spread all over the country (4).

However, it was reported that the mortality of COVID-19 was unbalanced in different regions (4). Briefly speaking, the mortality in Wuhan city was generally higher than that in other cities, and the mortality in Hubei Province was generally higher than that in nonHubei regions (i.e. 33 other provinces in China except Hubei). Specific reasons need to be investigated so that we can better control the epidemic.

52 Despite receiving assistance nationwide, Wuhan, as the source of the epidemic in China, 
54 doctor and could not be hospitalized in time. The medical resources consumed by

55 rescuing such patients further compressed the treatment options of other patients. Such

56

57

58

59

60

61

62

64

a vicious circle caused by inappropriate resource allocation might be one of the reasons for the high mortality in Wuhan. In addition, by reviewing the outbreak of severe acute respiratory syndrome (SARS) in Guangdong in 2003, we could find that the SARS pandemic gradually subsided with the warming of the weather, and was basically controlled in the warm April and May. It was also reported that air temperature (AT) and other environmental factors, such as relative humidity $(\mathrm{RH})$ and wind speed, might affect the SARS pandemic (5). Therefore, we assumed that differences in environmental factors in different regions might have contributed to the unbalanced mortality rate.

The first three makeshift hospitals (MSHs) Fangcang, Huoshenshan, and Leishenshan had been put into operation starting 5th of February 2020 (6). MSHs are mobile medical systems used in the field and are composed of several movable cabins. They have multiple functions, such as emergency treatment, surgical disposal, clinical examination, and so on. In case of any public health emergency, the cabins can build on the spot as soon as possible, and then in situ expand to a class II hospital (7). In the present study, we aimed to investigate whether these MSHs could reduce the mortality of COVID-19. Besides, we also investigated whether $\mathrm{AT}, \mathrm{RH}$, or air quality index (AQI, and the higher it is, the worser the air quality is) could affect the survival of COVID-19 patients.

\section{Materials \& Methods}

Data collection and mortality calculation

6 From January 21 to February 21, 2020, daily total number of confirmed cases by nucleic 77 acid testing, daily total number of severe cases (i.e. confirmed cases who met one of the 
78 following conditions: 1 . Respiratory rate $\geqslant 30$ times per minute; 2 . Resting state oxygen

79 saturation $\leqslant 93 \% ; 3$. Partial arterial pressure of oxygen $(\mathrm{PaO} 2) /$ concentration of oxygen

$80(\mathrm{FiO} 2) \leqslant 300 \mathrm{mmHg})(8)$, and daily total number of deaths in Wuhan city, Hubei Province

81 and non-Hubei regions (as a contrast so as to reduce bias) were collected by two authors

82 independently. All the above data were available on the official website of Chinese

83 National Health Commission (http://www.nhc.gov.cn/). Growth rate of confirmed cases

84 was calculated using the following formula:

85

$$
G R_{n}=\frac{N C_{n}}{T C_{(n-1)}}
$$

86 where

87

88

92
$\mathrm{GR}_{\mathrm{n}}=$ the growth rate on day $\mathrm{n}$

$\mathrm{NC}_{\mathrm{n}}=$ the new cases on day $\mathrm{n}$

$\mathrm{TC}_{(\mathrm{n}-1)}=$ the total cases on day $(\mathrm{n}-1)$

And the daily mortality rate was calculated using the following formulas:

$$
\begin{aligned}
& M C C_{n}=\frac{2 * N D_{n}}{T C C_{n}+T C C_{(n-1)}} \\
& M S C_{n}=\frac{2 * N D_{n}}{T S C_{n}+T S C_{(n-1)}}
\end{aligned}
$$

where

$$
\begin{aligned}
& M C C_{n}=\text { the mortality of confirmed cases on day n, } \\
& \mathrm{ND}_{n}=\text { the new deaths on day } n \text {, } \\
& \mathrm{TCC}_{n}=\text { the total confirmed cases on day } n, \\
& \mathrm{TCC}_{(\mathrm{n}-1)}=\text { the total confirmed cases on day }(n-1) \text {, } \\
& \mathrm{MSC}_{n}=\text { the mortality of confirmed cases on day n, }
\end{aligned}
$$


99

100

101

102

103

104 105

106

107

108

109

110

111

112

113

114

115

116

117

$\mathrm{TSC}_{\mathrm{n}}=$ the total severe cases on day $\mathrm{n}$, $\operatorname{TSC}_{(\mathrm{n}-1)}=$ the total severe cases on day $(\mathrm{n}-1)$.

The daily average data of three environmental factors, AT, RH, and AQI, were collected from Chinese Weather Net (http://www.weather.com.cn/), and the AT of Hubei Province was represented by the average AT of its seventeen cities (i.e. Wuhan, Huangshi, Shiyan, Yichang, Xiangyang, Ezhou, Jingmen, Xiaogan, Jingzhou, Huanggang, Xianning, Suizhou, Enshi, Xiantao, Qianjiang, Tianmen, and Shennongjia).

\section{Statistical analysis}

First, outliers of the datasets were detected and then deleted using SPSS software. Second, the data was transformed using z-score normalization, a method to standardize observations obtained at different times and from different cohorts, thus allowing comparisons between these observations (9). It was assumed that $T$ was the original time series and $Z$ was the Z-normalized time series:

$$
\begin{aligned}
& T=\left\{t_{1}, t_{2}, t_{3}, \ldots \ldots, t_{n}\right\} \\
& Z=\left\{z_{1}, z_{2}, z_{3}, \ldots \ldots, z_{n}\right\}
\end{aligned}
$$

Then

$$
z_{i}=\frac{\mathrm{t}_{i}-\mu_{T}}{\sigma_{T}}
$$

where $\mu_{T}$ and $\sigma_{T}$ were the arithmetic mean value and standard variance of sequence $T$.

The data of each region was then divided into group A (from January 21 to February 5, before the use of MSHs) and group B (from February 6 to February 21, after the use of MSHs). Since the sample size was small (less than 50 ), the normality of the data was determined using Shapiro-Wilk test, and $P$ value $>0.05$ was considered as 
122 normally distributed (10). If the data of the two groups were both normally distributed,

123 Student's t-test would be performed to compare their difference, and if the data of at least

124 one group had a skewed distribution, Mann-Whitney $U$ test would be performed instead

125 (11). We compared the data of four days, eight days, twelve days, and sixteen days after

126 the use of MSHs, respectively, with the data of sixteen days before the use of MSHs. As

127 for the correlation analysis, if the data of the environmental factors and the data of the 128 growth rate/mortality were both normally distributed, Pearson correlation analysis would 129 be performed to investigate the correlation between them, otherwise, Spearman's 130 correlation analysis would be performed instead (12). SPSS 26.0 statistical software 131 (IBM, New York, USA) was used for statistical data processing, and GraphPad Prism 8.3 132 (GraphPad Software Inc., New York, USA) was used to plot graphs. All tests were two133 sided, and $P$ value $<0.05$ was considered statistically significant.

134

135

136

137

138

139

140

141

142

143

144

145

\section{Results}

\section{Mortality difference before and after the use of MSHs}

Daily number of confirmed cases, severe cases, new deaths, and daily AT, RH, and AQI

in different regions were summarized in Table 1. The results of normality tests and the selection of statistical methods for comparative analyses are shown in Table 2. As shown in Figure 1 and Table 3, no matter on day 4, day 8, day 12, or day 16 after the use of MSHs, the growth rates of confirmed cases were all significantly decreased both in Wuhan and Hubei; but in non-Hubei regions, changes were also significant.

As shown in Figure 2 and Table 3, eight days after the use of MSHs, the mortality of confirmed cases was significantly decreased both in Wuhan $(\mathrm{t}=4.545, P<0.001)$ and Hubei $(U=0, P<0.001)$, (t and $U$ are the test statistic used to test the significance of the 
146 difference), while in non-Hubei regions, in contrast, the mortality of confirmed cases

147 remained unchanged $(U=76, P=0.106)$. While on day 12 and day 16 after the use of

$148 \mathrm{MSHs}$, the reduce in mortality was still significant both in Wuhan and Hubei; but in non-

149 Hubei regions, the reduce also became significant this time $(U=123, P=0.036 ; U=171$, $150 P=0.015$, respectively).

151 As shown in Figure $\mathbf{3}$ and Table 3, four days after the use of MSHs, the mortality of 152 severe cases was significantly decreased in Hubei $(U=0, P=0.002)$; and in non-Hubei 153 regions, in contrast, changes were not significant $(U=48, P=0.080)$. Similarly, on day 1548 , day 12 , and day 16 after the use of MSHs, the reduce in mortality was still significant 155 both in Wuhan and Hubei; but in non-Hubei regions, the reduce also became significant $156(U=82, P=0.039 ; U=129, P=0.015$; and $U=177, P=0.007$, respectively $)$.

157 In brief, the mortality of confirmed and severe cases was found to be significantly 158 decreased after the use of MSHs both in Wuhan and Hubei; while in non-Hubei regions, 159 the reduction in mortality was not significant on day $4 /$ day 8 , but became significant over 160 time.

\section{Correlation between environmental factors and outcomes}

163 The results of normality tests and the selection of statistical methods for correlation 164 analyses are shown in Table 4. As shown in Figure 4. The negative correlation between 165 the growth rate of confirmed cases and AT was not significant in Wuhan $(P=0.580)$, but 166 significant in Hubei region $(r=-0.644, P<0.001)$. There was a significant negative 167 correlation between AT and the mortality of confirmed cases both in Wuhan $(r=-0.460$, $168 P=0.014)$ and Hubei $(r=-0.535, P=0.004)$. And the mortality of severe patients was 
169 also found to be negatively correlated with AT in Hubei $(r=-0.522, P=0.005)$. This means

170 that, if the AT rises 1 Celsius, the mortality of confirmed cases would drop by about $0.5 \%$

171 and the mortality of severe cases would drop by $0.522 \%$ on average.

172 As shown in Figure 5, no significant correlation between the growth rate of 173 confirmed cases and $\mathrm{RH}$ was found no matter in Wuhan $(P=0.946)$ or Hubei $(P=0.144)$.

174 The correlation between the mortality of confirmed cases and $\mathrm{RH}$ was also insignificant 175 both in Wuhan $(P=0.943)$ and Hubei $(P=0.107)$. As for the mortality of severe cases, 176 its correlation with $\mathrm{RH}$ in Hubei was also found to be insignificant $(P=0.128)$.

177 As shown in Figure 6, the growth rate of confirmed cases was found to be 178 significantly correlated with AQI both in Wuhan $(r=0.373, P=0.042)$ and Hubei $(r=$ $1790.426, P=0.021)$. And the correlation between the mortality of confirmed cases and AQI 180 was also significant in Wuhan $(r=0.620, P<0.001)$ and Hubei $(r=0.634, P<0.001)$. As

181 for the mortality of severe cases, its correlation with AQI in Hubei was also significant $(r$ $182=0.622, P<0.001)$. This means that, if the AQI drops 1 unit, the mortality of confirmed 183 cases might drop by about $0.63 \%$ and the mortality of severe cases might drop by about 184 $0.622 \%$.

In brief, the mortality of confirmed/severe cases was negatively correlated with AT 186 no matter in Wuhan or in Hubei, while the negative correlation between the growth rate 187 of confirmed cases and AT was significant in Hubei, but not significant in Wuhan. In addition, both the growth rate and the mortality of COVID-19 cases were significantly correlated with $\mathrm{AQI}$, but not with $\mathrm{RH}$. 
193 and Hubei was significantly decreased compared with non-Hubei regions at the 194 beginning. The results preliminarily verified that these MSHs were beneficial to the 195 survival of COVID-19 patients. After the MSHs operated effectively, they could focus on 196 the isolation and treatment of patients with mild symptoms, thereby reducing the pressure 197 placed on traditional hospitals, so that the later could devote more energy to rescuing 198 patients with severe symptoms. In this way, medical resources could be better utilized 199 and patients could be better treated, and this might be the mechanism through which 200 MSHs worked. Later, with the passing of time, the difference in mortality before and after 201 the use of MSHs was still significant both in Wuhan and Hubei. However, the difference 202 became also significant in the non-Hubei regions, which means that some other factors 203 might also contribute to reducing the mortality. We thought that the accumulation of 204 medical staff's treatment experience might be one of the potential reasons. In addition, 205 according to the trade-off hypothesis, a pathogen must multiply within the host to ensure 206 transmission, while simultaneously maintaining opportunities for transmission by avoiding 207 host morbidity or death (13); this means that SARS-CoV-2 with weak virulence was more 208 likely to spread than that with strong virulence, which might explain why the mortality in 209 non-Hubei regions also decreased over time. However, empirical evidence remains 210 scarce and the truth needs to be further investigated.

211 Our study also found that the rise of AT could significantly reduce the mortality of both 212 confirmed and severe cases. According to a previous study, the deaths that occurred 213 were mainly elderly people who had comorbidities or surgery history before admission 214 (14). Acute or chronic cold exposure was reported to have adverse effects on the 215 respiratory system, such as increasing pulmonary vascular resistance, increasing 
216 numbers of goblet cells and mucous glands, and increasing muscle layers of terminal 217 arteries and arterioles, which might be associated with the symptoms of chronic 218 obstructive pulmonary disease, high altitude pulmonary hypertension, and right heart 219 hypertrophy (15). It was also reported that cold exposure was usually accompanied by 220 hormonal changes, which might directly or indirectly alter the immune system (16). The 221 above factors would worsen the underlying medical conditions of elderly people, and this 222 might explain why warm weather could reduce the mortality of COVID-19 patients. When 223 it comes to the transmissibility of coronavirus, a previous in vitro study found that when 224 the AT was lower, gastroenteritis virus and mouse hepatitis virus could survive longer on 225 stainless steel surface than when the AT was higher (17). A case-crossover analysis 226 performed in Saudi Arabia also found that primary Middle East Respiratory Syndrome 227 were more likely to occur when the climate was relatively cold and dry (18). Some earlier 228 studies on SARS also pointed out that the SARS cases were negatively correlated with 229 AT (19), and it was estimated that in days with a lower AT during the epidemic, the risk 230 of increased daily incidence of SARS was 18.18-fold (95\% confidence interval 5.6-58.8) 231 higher than in days with a higher AT (20); and as the AT rose, SARS cases tended to 232 decrease afterwards (21). In our study, although the growth rate of confirmed cases was 233 found to be negatively correlated with AT in Hubei Province, the correlation was not 234 significant in Wuhan City. The specific reason for this inconsistency needs to be further 235 investigated, and one of the potential reasons might be that the basic number of COVID236 19 cases in Wuhan was so large that the change of AT was not enough to affect the disease transmission. In addition, it was proposed by Tan et al. (22) that the optimal AT 238 for SARS occurrence was $16^{\circ} \mathrm{C}$ to $28^{\circ} \mathrm{C}$ and $18^{\circ} \mathrm{C}$ to $22^{\circ} \mathrm{C}(23)$; while in our study, the 
239 daily AT were all less than $13^{\circ} \mathrm{C}$, therefore, another potential reason might be that the 240 current AT was not high enough to exert a significant impact on SARS-CoV-2. As the AT 241 rises, subsequent studies including more regions and a wider range of AT are necessary 242 to further validate our results.

243 As for $\mathrm{RH}$, it was reported that compared with other human coronaviruses, SARS 244 coronaviruses and MERS coronaviruses appeared to have an unusual capacity to survive 245 on dry surfaces (24-28). SARS coronaviruses could survive for more than 6 days when 246 dried on a Petri dish, while human coronavirus HCoV-229E could only survive for less 247 than 3 days (25). It was also reported that SARS coronavirus viability was lost more 248 rapidly at higher $\mathrm{RH}$ (e.g., $\mathrm{RH}$ of $>95 \%$ ) than at lower $\mathrm{RH}$ (e.g., $\mathrm{RH}$ of $40-50 \%$ ) (24). 249 However, in our study, no significant correlation between $\mathrm{RH}$ and the growth rate/mortality 250 of COVID-19 cases was found. The relatively small sample size and the small range of daily $\mathrm{RH}$ in our study (most are of $75-95 \%$ ) might be one of the potential reasons for our 252 negative results. Besides, as a new type of coronaviruses, SARS-CoV-2 might have obtained the ability to withstand higher $\mathrm{RH}$. In any case, more studies are still needed to 254 further investigate the correlation between $\mathrm{RH}$ and the growth rate/mortality of COVID-19 255 cases.

256 Another discovery of our study was that both the growth rate and mortality of COVID25719 were significantly correlated with AQI. This means that the worse the air quality is, the 258 higher the growth rate/mortality of COVID-19 might be. This finding was consistent with 259 a previous study, in which patients in regions with moderate air pollution levels were found 260 to be more likely to die than those in regions with low air pollution levels. Prolonged 261 exposure to air pollution has been linked to acute respiratory inflammation, asthma attack, 
262 and death from cardiorespiratory diseases in various studies (29-32). 263 Several potential mechanistic pathways have also been described, which include 264 oxidative injury to the airways, leading to inflammation, enhanced 265 coagulation/thrombosis, a propensity for arrhythmias, acute arterial vasoconstriction, 266 systemic inflammation responses, and the chronic promotion of atherosclerosis $(33,34)$. 267 These factors could increase the vulnerability of a population to COVID-19 and aggravate 268 the respiratory and pre-existing cardiovascular symptoms of COVID-19 patients, which 269 might explain the significant correlation between the growth rate/mortality of COVID-19 270 cases and AQI.

271 In this study, we tried to evaluate the effects of MSHs and explore the relation between 272 environmental factors and the growth rate/mortality of COVID-19. We believe that our 273 findings will give some guidance to the current anti-epidemic work and future research. 274 Nevertheless, there are some limitations in our study that should be discussed. First, we 275 could not exclude effects of many other factors, such as ultraviolet intensity, wind speed, 276 air pressure and so on, on the disease transmission or severity, but we could not 277 specifically address these parameters due to lack of data. Second, since most patients 278 were isolated at home or in MSHs, where the temperature was slightly different from the 279 AT outside, some deviation might have been caused. Third, the sample size of 32 days 280 was not so big for the comparisons and correlation analyses, which might have also 281 caused some selection bias.

\section{Conclusions}

284 In conclusion, the use of MSHs, the rise of AT, and the improvement of air quality were 285 all found to be associated with a better survival of COVID-19 patients, while RH seemed 
286 to have no effect on the growth rate/mortality of COVID-19 patients. Since the sample 287 size in our study was rather small, studies including more regions and larger sample size 288 are urgently needed to further validate our findings.

289

290

291

292

293

294

295

296

297

298

299

300

301

302

303

304

305

306

307

308

309

310

\section{Acknowledgements}

Not applicable

\section{References}

1. Wu F, Zhao S, Yu B, Chen Y-M, Wang W, Song Z-G, Hu Y, Tao Z-W, Tian J-H, Pei

Y-Y, Yuan M-L, Zhang Y-L, Dai F-H, Liu Y, Wang Q-M, Zheng J-J, Xu L, Holmes EC, and Zhang Y-Z. 2020. A new coronavirus associated with human respiratory disease in

China. Nature 579:265-269. 10.1038/s41586-020-2008-3

2. Gorbalenya AE, Baker SC, Baric RS, de Groot RJ, Drosten C, Gulyaeva AA, Haagmans BL, Lauber C, Leontovich AM, Neuman BW, Penzar D, Perlman S, Poon

LLM, Samborskiy DV, Sidorov IA, Sola I, Ziebuhr J, and Coronaviridae Study Group of the International Committee on Taxonomy of V. 2020. The species Severe acute respiratory syndrome-related coronavirus: classifying 2019-nCoV and naming it SARS-

CoV-2. Nature Microbiology 5:536-544. 10.1038/s41564-020-0695-z

3. Chan JF-W, Yuan S, Kok K-H, To KK-W, Chu H, Yang J, Xing F, Liu J, Yip CC-Y, Poon RW-S, Tsoi H-W, Lo SK-F, Chan K-H, Poon VK-M, Chan W-M, Ip JD, Cai J-P, Cheng VC-C, Chen H, Hui CK-M, and Yuen K-Y. 2020. A familial cluster of pneumonia associated with the 2019 novel coronavirus indicating person-to-person transmission: a study of a family cluster. The Lancet 395:514-523. 10.1016/S0140-6736(20)30154-9 4. Novel CPERE. [The epidemiological characteristics of an outbreak of 2019 novel coronavirus diseases (COVID-19) in China]. Zhonghua liu xing bing xue za zhi = 
311 Zhonghua liuxingbingxue zazhi 41:145-151. 10.3760/cma.j.issn.0254-6450.2020.02.003

312 5. Yuan J, Yun H, Lan W, Wang W, Sullivan SG, Jia S, and Bittles AH. 2006. A

313 climatologic investigation of the SARS-CoV outbreak in Beijing, China. American

314 Journal of Infection Control 34:234-236. 10.1016/j.ajic.2005.12.006

315 6. China Central Television. Makeshift hospitals start to accept patients in Wuhan.

316 http://english.cctv.com/2020/02/06/ARTIxIHp9AN2fAStmOl5jYeE200206.shtml

317 Published 2020. Accessed February 22, 2020.

318 7. Bai S, Yu BG, Zhang YZ, Ding H, Wu ZW, Fan B, Fan HJ, Hou SK, and Chen F.

319 2018. Challenges of Treating Adenovirus Infection: Application of a Deployable Rapid-

320 Assembly Shelter Hospital. Disaster medicine and public health preparedness 12:109-

321 114. 10.1017/dmp.2016.187

322 8.Xinyi X, Yuanyuan C. 2020. Consensus on the diagnosis, treatment and management

323 of COVID-19. Available at http://health.people.com.cn/n1/2020/0211/c14739-

324 31581678.html (accessed 22 February 2020)

325 9. Guilloux JP, Seney M, Edgar N, and Sibille E. 2011. Integrated behavioral z-scoring 326 increases the sensitivity and reliability of behavioral phenotyping in mice: relevance to 327 emotionality and sex. J Neurosci Methods 197:21-31. 10.1016/j.jneumeth.2011.01.019 328 10. Mishra P, Pandey CM, Singh U, Gupta A, Sahu C, and Keshri A. 2019. Descriptive 329 statistics and normality tests for statistical data. Annals of cardiac anaesthesia 22:67-72.

330 10.4103/aca.ACA_157_18

331 11. Parab S, Bhalerao S. 2010. Choosing statistical test. International Journal of

332 Ayurveda Ressearch 1:187-91. 10.4103/0974-7788.72494

333 12. Schober P, Boer C, Schwarte LA. 2018. Correlation Coefficients: Appropriate Use 
334 and Interpretation. Anesth Analg 126:1763-1768. 10.1213/ane.0000000000002864

335 13. Blanquart F, Grabowski MK, Herbeck J, Nalugoda F, Serwadda D, Eller MA, Robb

336 ML, Gray R, Kigozi G, Laeyendecker O, Lythgoe KA, Nakigozi G, Quinn TC, Reynolds

337 SJ, Wawer MJ, and Fraser C. 2016. A transmission-virulence evolutionary trade-off

338 explains attenuation of HIV-1 in Uganda. eLife 5. 10.7554/eLife.20492

339 14. Chen N, Zhou M, Dong X, Qu J, Gong F, Han Y, Qiu Y, Wang J, Liu Y, Wei Y, Xia

340 Ja, Yu T, Zhang X, and Zhang L. 2020. Epidemiological and clinical characteristics of 99

341 cases of 2019 novel coronavirus pneumonia in Wuhan, China: a descriptive study. The

342 Lancet 395:507-513. 10.1016/S0140-6736(20)30211-7

343 15. Giesbrecht GG. 1995. The respiratory system in a cold environment. Aviation,

344 space, and environmental medicine 66:890-902.

345 16. van der Lans AAJJ, Boon MR, Haks MC, Quinten E, Schaart G, Ottenhoff TH, and

346 van Marken Lichtenbelt WD. 2015. Cold acclimation affects immune composition in

347 skeletal muscle of healthy lean subjects. Physiological reports 3. 10.14814/phy2.12394

348 17. Casanova LM, Jeon S, Rutala WA, Weber DJ, and Sobsey MD. 2010. Effects of air

349 temperature and relative humidity on coronavirus survival on surfaces. Applied and

350 environmental microbiology 76:2712-2717. 10.1128/aem.02291-09

351 18. Gardner EG, Kelton D, Poljak Z, Van Kerkhove M, von Dobschuetz S, and Greer

352 AL. 2019. A case-crossover analysis of the impact of weather on primary cases of

353 Middle East respiratory syndrome. BMC infectious diseases 19:113. 10.1186/s12879-

$354 \quad 019-3729-5$

355 19. Bi P, Wang J, and Hiller JE. 2007. Weather: driving force behind the transmission of

356 severe acute respiratory syndrome in China? Intern Med J 37:550-554. 10.1111/j.1445- 
357

358

359

360

361

362 363

364 365 366 367 368 369 370

371 372 373 374 375 376

377 378 379

5994.2007.01358.x

20. Lin KUN, Yee-Tak Fong D, Zhu B, and Karlberg J. 2006. Environmental factors on the SARS epidemic: air temperature, passage of time and multiplicative effect of hospital infection. Epidemiology and Infection 134:223-230.

\subsection{7/S0950268805005054}

21. Yip C, Chang WL, Yeung K, and Yu ITS. 2007. Possible meteorological influence on the Severe Acute Respiratory Syndrome (SARS) community outbreak at Amoy Gardens, Hong Kong. Journal of environmental health 70:39-46.

22. Tan J, Mu L, Huang J, Yu S, Chen B, and Yin J. 2005. An initial investigation of the association between the SARS outbreak and weather: with the view of the environmental temperature and its variation. J Epidemiol Community Health 59:186192. $10.1136 /$ jech. 2004.020180

23. Lee A. 2003. Host and environment are key factors. J Epidemiol Community Health 57:770. 10.1136/jech.57.10.770

24. Chan KH, Peiris JSM, Lam SY, Poon LLM, Yuen KY, and Seto WH. 2011. The Effects of Temperature and Relative Humidity on the Viability of the SARS Coronavirus. Advances in Virology 2011:734690. 10.1155/2011/734690

25. Rabenau HF, Cinatl J, Morgenstern B, Bauer G, Preiser W, and Doerr HW. 2005. Stability and inactivation of SARS coronavirus. Med Microbiol Immunol 194:1-6.

$10.1007 / \mathrm{s} 00430-004-0219-0$

26. Müller A, Tillmann RL, Müller A, Simon A, and Schildgen O. 2008. Stability of human metapneumovirus and human coronavirus NL63 on medical instruments and in the patient environment. J Hosp Infect 69:406-408. 10.1016/j.jhin.2008.04.017 
380

381

382 383 384 385 386 387 388 389 390 391 392 393 394 395 396

397 33. Guarnieri M, and Balmes JR. 2014. Outdoor air pollution and asthma. Lancet 398 (London, England) 383:1581-1592. 10.1016/s0140-6736(14)60617-6

399 34. Brook RD, Franklin B, Cascio W, Hong Y, Howard G, Lipsett M, Luepker R, 400 Mittleman M, Samet J, Smith SC, Jr., and Tager I. 2004. Air pollution and 401 cardiovascular disease: a statement for healthcare professionals from the Expert Panel 402 on Population and Prevention Science of the American Heart Association. Circulation

27. Sizun J, Yu MWN, and Talbot PJ. 2000. Survival of human coronaviruses 229E and OC43 in suspension and after drying onsurfaces: a possible source ofhospital-acquired infections. Journal of Hospital Infection 46:55-60. 10.1053/jhin.2000.0795

28. Dowell SF, Simmerman JM, Erdman DD, Wu JS, Chaovavanich A, Javadi M, Yang JY, Anderson LJ, Tong S, and Ho MS. 2004. Severe acute respiratory syndrome coronavirus on hospital surfaces. Clin Infect Dis 39:652-657. 10.1086/422652

29. Bates DV, Baker-Anderson M, and Sizto R. 1990. Asthma attack periodicity: a study of hospital emergency visits in Vancouver. Environ Res 51:51-70. 10.1016/s00139351(05)80182-3

30. Schwartz J, and Dockery DW. 1992. Particulate Air Pollution and Daily Mortality in Steubenville, Ohio. American Journal of Epidemiology 135:12-19.

10.1093/oxfordjournals.aje.a116195

31. Dockery DW, and Pope CA, 3rd. 1994. Acute respiratory effects of particulate air pollution. Annu Rev Public Health 15:107-132. 10.1146/annurev.pu.15.050194.000543

32. Schwartz J, Slater D, Larson TV, Pierson WE, and Koenig JQ. 1993. Particulate air pollution and hospital emergency room visits for asthma in Seattle. Am Rev Respir Dis 147:826-831. 10.1164/ajrccm/147.4.826 
403 109:2655-2671. 10.1161/01.Cir.0000128587.30041.C8 


\section{Table 1 (on next page)}

Daily total number of confirmed cases, severe cases, new deaths and daily AT, RH, and $A Q I$ in different regions 
1 Table 1: Daily total number of confirmed cases, severe cases, new deaths and daily AT, RH, and AQI in different regions

\begin{tabular}{|c|c|c|c|c|c|c|c|c|c|c|c|c|c|c|}
\hline \multirow[b]{4}{*}{ Date } & \multicolumn{3}{|c|}{ Wuhan } & \multicolumn{8}{|c|}{ Hubei } & \multicolumn{3}{|c|}{ Non-Hubei regions } \\
\hline & \multirow{3}{*}{$\begin{array}{l}\text { Daily total } \\
\text { confirmed } \\
\text { cases }\end{array}$} & \multirow{3}{*}{$\begin{array}{l}\text { Daily } \\
\text { deaths }\end{array}$} & \multirow[b]{3}{*}{ AT } & \multirow{3}{*}{$\begin{array}{l}\text { RH } \\
(\%)\end{array}$} & \multirow{3}{*}{ AQI } & \multirow{3}{*}{$\begin{array}{l}\text { Daily total } \\
\text { confirmed } \\
\text { cases }\end{array}$} & \multirow{3}{*}{$\begin{array}{l}\text { Daily total } \\
\text { severe cases }\end{array}$} & \multicolumn{2}{|l|}{ Daily } & \multirow{3}{*}{$\begin{array}{l}\mathrm{RH} \\
(\%)\end{array}$} & \multirow{3}{*}{ AQI } & \multirow{3}{*}{$\begin{array}{l}\text { Daily total } \\
\text { confirmed } \\
\text { cases }\end{array}$} & \multirow{3}{*}{$\begin{array}{l}\text { Daily total } \\
\text { severe cases }\end{array}$} & \multirow{3}{*}{$\begin{array}{l}\text { Daily } \\
\text { deaths }\end{array}$} \\
\hline & & & & & & & & & & & & & & \\
\hline & & & & & & & & deaths & AT & & & & & \\
\hline 20-Jan & 258 & 6 & - & - & - & 270 & 51 & 6 & - & - & - & 21 & 17 & 0 \\
\hline 21-Jan & 363 & 3 & 6.0 & 90.0 & 104.0 & 375 & 65 & 3 & 5.5 & 90.9 & 130.3 & 65 & 37 & 0 \\
\hline 22-Jan & 425 & 8 & 4.0 & 91.0 & 106.0 & 444 & 71 & 8 & 4.7 & 94.3 & 105.2 & 127 & 24 & 0 \\
\hline 23-Jan & 495 & 6 & 5.0 & 96.0 & 49.0 & 549 & 129 & 7 & 4.9 & 94.6 & 76.5 & 281 & 48 & 1 \\
\hline 24-Jan & 572 & 15 & 5.5 & 94.0 & 61.0 & 729 & 157 & 15 & 4.5 & 92.5 & 61.8 & 558 & 80 & 1 \\
\hline 25-Jan & 618 & 7 & 3.0 & 89.0 & 81.0 & 1052 & 192 & 13 & 3.3 & 87.9 & 74.2 & 923 & 132 & 2 \\
\hline 26-Jan & 698 & 18 & 2.0 & 81.0 & 97.0 & 1423 & 290 & 24 & 2.3 & 83.0 & 81.6 & 1321 & 171 & 0 \\
\hline 27-Jan & 1590 & 22 & 2.5 & 92.0 & 90.0 & 2567 & 690 & 24 & 2.4 & 86.7 & 74.2 & 1948 & 286 & 2 \\
\hline 28-Jan & 1905 & 19 & 3.5 & 91.0 & 87.0 & 3349 & 899 & 25 & 3.9 & 87.1 & 78.1 & 2625 & 340 & 1 \\
\hline 29-Jan & 2261 & 25 & 5.5 & 94.0 & 96.0 & 4334 & 988 & 37 & 5.6 & 86.0 & 87.8 & 3377 & 382 & 1 \\
\hline 30-Jan & 2639 & 30 & 6.0 & 95.0 & 117.0 & 5486 & 1094 & 42 & 6.5 & 73.5 & 93.5 & 4206 & 433 & 1 \\
\hline 31-Jan & 3215 & 33 & 6.5 & 93.0 & 102.0 & 6738 & 1294 & 45 & 7.2 & 70.9 & 109.8 & 5053 & 501 & 1 \\
\hline 1-Feb & 4109 & 32 & 8.5 & 79.0 & 65.0 & 8565 & 1562 & 45 & 7.5 & 73.2 & 85.8 & 5815 & 548 & 0 \\
\hline 2-Feb & 5142 & 41 & 8.5 & 85.0 & 121.0 & 9618 & 1701 & 56 & 7.4 & 85.4 & 112.3 & 7587 & 595 & 1 \\
\hline $3-\mathrm{Feb}$ & 6384 & 48 & 6.0 & 93.0 & 69.0 & 10990 & 2143 & 64 & 6.3 & 84.4 & 104.5 & 9448 & 645 & 0 \\
\hline 4-Feb & 8351 & 49 & 7.0 & 94.0 & 183.0 & 12627 & 2520 & 65 & 7.7 & 85.3 & 119.8 & 11697 & 699 & 0 \\
\hline 5-Feb & 10117 & 52 & 9.0 & 76.0 & 20.0 & 14314 & 3084 & 70 & 8.3 & 82.1 & 46.6 & 11988 & 775 & 3 \\
\hline 6-Feb & 11618 & 64 & 5.0 & 92.0 & 47.0 & 15804 & 4002 & 69 & 3.8 & 92.7 & 48.5 & 13181 & 819 & 4 \\
\hline 7-Feb & 13603 & 67 & 4.5 & 84.0 & 51.0 & 19835 & 5195 & 81 & 4.2 & 88.5 & 53.4 & 11939 & 906 & 5 \\
\hline 8-Feb & 14982 & 63 & 5.5 & 96.0 & 66.0 & 20993 & 5247 & 81 & 6.4 & 87.5 & 62.7 & 12745 & 941 & 8 \\
\hline 9-Feb & 16902 & 73 & 7.0 & 97.0 & 61.0 & 22160 & 5505 & 91 & 7.7 & 80.8 & 58.5 & 13822 & 979 & 6 \\
\hline $10-\mathrm{Feb}$ & 18454 & 67 & 7.5 & 89.0 & 55.0 & 25087 & 6344 & 103 & 8.2 & 90.4 & 59.5 & 12539 & 989 & 5 \\
\hline
\end{tabular}

2 Table 1 (continued)

Wuhan

Hubei

Non-Hubei regions 


\begin{tabular}{|c|c|c|c|c|c|c|c|c|c|c|c|c|c|c|}
\hline \multirow[b]{2}{*}{ Date } & \multirow{2}{*}{$\begin{array}{l}\text { Daily total } \\
\text { confirmed } \\
\text { cases }\end{array}$} & \multirow{2}{*}{\multicolumn{2}{|c|}{ Daily }} & \multirow{2}{*}{$\begin{array}{l}\text { RH } \\
(\%)\end{array}$} & \multirow[b]{2}{*}{ AQI } & \multirow{2}{*}{$\begin{array}{l}\text { Daily total } \\
\text { confirmed } \\
\text { cases }\end{array}$} & \multirow{2}{*}{$\begin{array}{l}\text { Daily total } \\
\text { severe cases }\end{array}$} & \multicolumn{2}{|l|}{ Daily } & \multirow{2}{*}{$\begin{array}{l}\text { RH } \\
(\%)\end{array}$} & \multirow[b]{2}{*}{ AQI } & \multirow{2}{*}{$\begin{array}{l}\text { Daily total } \\
\text { confirmed } \\
\text { cases }\end{array}$} & \multirow{2}{*}{$\begin{array}{l}\text { Daily total } \\
\text { severe cases }\end{array}$} & \multirow{2}{*}{$\begin{array}{l}\text { Daily } \\
\text { deaths }\end{array}$} \\
\hline & & & & & & & & deaths & AT & & & & & \\
\hline $11-\mathrm{Feb}$ & 19558 & 72 & 9.0 & 93.0 & 56.0 & 26121 & 7241 & 94 & 9.2 & 93.4 & 57.7 & 12679 & 963 & 3 \\
\hline $12-\mathrm{Feb}$ & 30043 & 82 & 11.0 & 97.0 & 50.0 & 43455 & 7084 & 107 & 10.7 & 93.4 & 53.5 & 9071 & 946 & 12 \\
\hline $13-\mathrm{Feb}$ & 32959 & 88 & 13.0 & 91.0 & 81.0 & 46806 & 9278 & 108 & 12.6 & 94.0 & 66.8 & 8942 & 926 & 5 \\
\hline 14-Feb & 34289 & 77 & 11.0 & 92.0 & 36.0 & 48175 & 10152 & 105 & 10.2 & 81.2 & 27.8 & 8698 & 901 & 4 \\
\hline $15-\mathrm{Feb}$ & 35314 & 110 & 0.5 & 95.0 & 39.0 & 49030 & 10396 & 139 & 0.5 & 83.1 & 32.0 & 8386 & 876 & 3 \\
\hline $16-\mathrm{Feb}$ & 36385 & 76 & 2.0 & 95.0 & 30.0 & 49847 & 9797 & 100 & 3.8 & 78.6 & 34.1 & 8087 & 847 & 5 \\
\hline 17-Feb & 37152 & 72 & 5.0 & 92.0 & 47.0 & 50338 & 10970 & 93 & 6.3 & 67.8 & 41.4 & 7678 & 771 & 5 \\
\hline $18-\mathrm{Feb}$ & 38020 & 116 & 7.5 & 59.0 & 59.0 & 50633 & 11246 & 132 & 7.3 & 57.7 & 67.1 & 7172 & 731 & 4 \\
\hline 19-Feb & 37994 & 88 & 8.0 & 94.0 & 47.0 & 49665 & 11178 & 108 & 8.2 & 79.5 & 61.1 & 6638 & 686 & 6 \\
\hline $20-\mathrm{Feb}$ & 37448 & 99 & 10.0 & 75.0 & 80.0 & 48730 & 10997 & 115 & 9.9 & 67.5 & 65.5 & 6235 & 636 & 3 \\
\hline $21-\mathrm{Feb}$ & 36680 & 90 & 9.0 & 83.0 & 80.0 & 47647 & 10892 & 106 & 9.2 & 81.4 & 74.6 & 5637 & 585 & 3 \\
\hline
\end{tabular}




\section{Table 2 (on next page)}

Tests of normality and selection of statistical methods for analyses of comparisons of 16 days before and $4,8,12$, or 16 days after the use of MSHs. 
1 Table 2: Tests of normality and selection of statistical methods for analyses of comparisons of 16 days before and 4 , 28,12 , or 16 days after the use of MSHs.

\begin{tabular}{|c|c|c|c|c|c|}
\hline & \multirow[b]{2}{*}{ Group } & \multicolumn{3}{|c|}{ Shapiro-Wilk } & \multirow[b]{2}{*}{ Selected statistical methods } \\
\hline & & Statistic & $\mathrm{df}$ & $P$ value ${ }^{1}$ & \\
\hline \multirow[t]{4}{*}{ GRW } & Before & 0.950 & 15 & $=0.526$ & \\
\hline & After 4 & 0.996 & 4 & $=0.986$ & Student's t test \\
\hline & After 8 & 0.969 & 7 & $=0.894$ & Student's t test \\
\hline & After 12 & 0.928 & 11 & $=0.392$ & Student's t test \\
\hline$\square$ & After 16 & 0.944 & 15 & $=0.434$ & Student's t test \\
\hline $\mathrm{MCW}$ & Before & 0.893 & 14 & $=0.089$ & \\
\hline \multirow[t]{4}{*}{$\square$} & After 4 & 0.886 & 3 & $=0.342$ & Student's t test \\
\hline & After 8 & 0.982 & 7 & $=0.968$ & Student's t test \\
\hline & After 12 & 0.960 & 11 & $=0.776$ & Student's t test \\
\hline & After 16 & 0.932 & 15 & $=0.289$ & Student's t test \\
\hline \multirow[t]{4}{*}{ GRH } & Before & 0.957 & 15 & $=0.635$ & \\
\hline & After 4 & 0.792 & 4 & $=0.089$ & Student's t test \\
\hline & After 8 & 0.811 & 7 & $=0.053$ & Student's t test \\
\hline & After 12 & 0.805 & 11 & $=0.011$ & Mann-Whitney U test \\
\hline$\square$ & After 16 & 0.836 & 15 & $=0.011$ & Mann-Whitney U test \\
\hline \multirow[t]{4}{*}{$\mathrm{MCH}$} & Before & 0.862 & 15 & $=0.026$ & \\
\hline & After 4 & 0.895 & 4 & $=0.408$ & Mann-Whitney U test \\
\hline & After 8 & 0.885 & 8 & $=0.210$ & Mann-Whitney U test \\
\hline & After 12 & 0.899 & 12 & $=0.156$ & Mann-Whitney U test \\
\hline$\square$ & After 16 & 0.873 & 16 & $=0.030$ & Mann-Whitney U test \\
\hline \multirow[t]{4}{*}{ MSH } & Before & 0.821 & 15 & $=0.007$ & \\
\hline & After 4 & 0.990 & 4 & $=0.955$ & Mann-Whitney U test \\
\hline & After 8 & 0.968 & 8 & $=0.883$ & Mann-Whitney U test \\
\hline & After 12 & 0.964 & 12 & $=0.845$ & Mann-Whitney U test \\
\hline$\square$ & After 16 & 0.933 & 16 & $=0.275$ & Mann-Whitney U test \\
\hline \multirow[t]{4}{*}{ GRNH } & Before & 0.860 & 15 & $=0.024$ & \\
\hline & After 4 & 0.761 & 4 & $=0.049$ & Mann-Whitney U test \\
\hline & After 8 & 0.890 & 7 & $=0.273$ & Mann-Whitney U test \\
\hline & After 12 & 0.917 & 11 & $=0.296$ & Mann-Whitney U test \\
\hline$\square$ & After 16 & 0.881 & 15 & $=0.049$ & Mann-Whitney U test \\
\hline $\mathrm{MCNH}$ & Before & 0.648 & 15 & $<0.001$ & \\
\hline \multirow[t]{4}{*}{$\square$} & After 4 & 0.938 & 4 & $=0.640$ & Mann-Whitney U test \\
\hline & After 8 & 0.977 & 7 & $=0.945$ & Mann-Whitney U test \\
\hline & After 12 & 0.944 & 11 & $=0.570$ & Mann-Whitney U test \\
\hline & After 16 & 0.967 & 15 & $=0.817$ & Mann-Whitney U test \\
\hline \multirow[t]{2}{*}{ MSNH } & Before & 0.704 & 15 & $<0.001$ & \\
\hline & After 4 & 0.898 & 4 & $=0.422$ & Mann-Whitney U test \\
\hline
\end{tabular}




$\begin{array}{lllll}\text { After 8 } & 0.926 & 7 & =0.521 & \text { Mann-Whitney U test } \\ \text { After 12 } & 0.938 & 11 & =0.494 & \text { Mann-Whitney U test } \\ \text { After 16 } & 0.918 & 15 & =0.181 & \text { Mann-Whitney U test }\end{array}$

$3 P>0.05$ was considered as normally distributed

4 Abbreviations: df, degree of Freedom; GRW, growth rate of confirmed cases in Wuhan; Before: before the use

5 of MSHs; After 4, 4 days after the use of MSHs; After 8, 8 days after the use of MSHs; After 12, 12 days after

6 the use of MSHs; After 16, 16 days after the use of MSHs; MCW: mortality of confirmed cases in Wuhan; GRH:

7 growth rate of confirmed cases in Hubei; $\mathrm{MCH}$ : mortality of confirmed cases in Hubei; MSH: mortality of severe

8 cases in Hubei; GRNH: growth rate of confirmed cases in non-Hubei regions; MCNH: mortality of confirmed

9 cases in non-Hubei regions; MSNH: mortality of severe cases in non-Hubei region; MSHs, "Fangcang,

10 Huoshenshan, and Leishenshan" makeshift hospitals. 


\section{Table 3 (on next page)}

The difference in the growth rate/mortality of COVID-19 before and after the use of MSHs 
1 Table 3: The difference in the growth rate/mortality of COVID-19 before and after the use of MSHs

\begin{tabular}{|c|c|c|c|c|}
\hline \multirow[t]{2}{*}{$\square$} & \multirow{2}{*}{$\begin{array}{l}\square \\
\text { Group }\end{array}$} & \multicolumn{3}{|c|}{ Mann-Whitney U test } \\
\hline & & Medium (LB, UB) & Test statistic ${ }^{1}$ & $P$ value ${ }^{2}$ \\
\hline \multirow[t]{5}{*}{ GRW } & Before & $0.211(0.167,0.255)$ & $\square$ & $\square$ \\
\hline & After 4 days & $0.137(0.090,0.184)$ & $\mathrm{t}=1.801$ & $=0.089$ \\
\hline & After 8 days & $0.097(0.079,0.149)$ & $\mathrm{t}=3.059$ & $=0.006$ \\
\hline & After 12 days & $0.084(0.049,0.118)$ & $t=4.656$ & $<0.001$ \\
\hline & After 16 days & $0.060(0.028,0.093)$ & $\mathrm{t}=5.889$ & $<0.001$ \\
\hline \multirow[t]{5}{*}{ GRH } & Before & $0.268(0.158,0.346)$ & & \\
\hline & After 4 days & $0.118(-0.031,0.268)$ & $\mathrm{t}=2.520$ & $=0.022$ \\
\hline & After 8 days & $0.103(0.035,0.171)$ & $\mathrm{t}=3.654$ & $=0.002$ \\
\hline & After 12 days & $0.072(0.024,0.121)$ & $U=8$ & $<0.001$ \\
\hline & After 16 days & $0.050(0.009,0.090)$ & $U=8$ & $<0.001$ \\
\hline \multirow[t]{5}{*}{ GRNH } & Before & $0.450(0.258,0.642)$ & & \\
\hline & After 4 days & $0.039(-0.104,0.183)$ & $U=3$ & $=0.004$ \\
\hline & After 8 days & $0.008(-0.066,0.083)$ & $U=3$ & $<0.001$ \\
\hline & After 12 days & $-0.008(-0.053,0.037)$ & $U=3$ & $<0.001$ \\
\hline & After 16 days & $-0.026(-0.061,0.010)$ & $U=3$ & $<0.001$ \\
\hline \multirow[t]{5}{*}{$\mathrm{MCW}(\%)$} & Before & $1.133(0.892,1.374)$ & & \\
\hline & After 4 days & $0.477(0.357,0.596)$ & $t=2.652$ & $=0.018$ \\
\hline & After 8 days & $0.340(0.322,0.478)$ & $t=4.545$ & $<0.001$ \\
\hline & After 12 days & $0.341(0.268,0.413)$ & $\mathrm{t}=6.812$ & $<0.001$ \\
\hline & After 16 days & $0.319(0.264,0.375)$ & $\mathrm{t}=7.102$ & $<0.001$ \\
\hline \multirow[t]{5}{*}{$\mathrm{MCH}(\%)$} & Before & $1.013(0.747,1.279)$ & & \\
\hline & After 4 days & $0.433(0.387,0.479)$ & $U=0$ & $=0 \cdot 001$ \\
\hline & After 8 days & $0.385(0.320,0.450)$ & $U=0$ & $<0.001$ \\
\hline & After 12 days & $0.331(0.266,0.397)$ & $U=0$ & $<0.001$ \\
\hline & After 16 days & $0.307(0.254,0.360)$ & $U=0$ & $<0.001$ \\
\hline \multirow[t]{5}{*}{ MCNH (\%) } & Before & $0.053(0.005,0.102)$ & & \\
\hline & After 4 days & $0.045(0.023,0.068)$ & $U=45$ & $=0.152$ \\
\hline & After 8 days & $0.043(0.030,0.056)$ & $U=76$ & $=0.106$ \\
\hline & After 12 days & $0.046(0.037,0.055)$ & $U=123$ & $=0.036$ \\
\hline & After 16 days & $0.049(0.041,0.058)$ & $U=171$ & $=0.015$ \\
\hline \multirow[t]{5}{*}{ MSH (\%) } & Before & $5.003(3.586,6.419)$ & & \\
\hline & After 4 days & $1.738(1.476,2.000)$ & $U=0$ & $=0.002$ \\
\hline & After 8 days & $1.337(1.002,1.657)$ & $U=0$ & $<0.001$ \\
\hline & After 12 days & $1.434(1.226,1.642)$ & $U=0$ & $<0.001$ \\
\hline & After 16 days & $1.335(1.157,1.514)$ & $U=0$ & $<0.001$ \\
\hline \multirow[t]{2}{*}{ MSNH (\%) } & Before & $0.398(0.071,0.724)$ & & \\
\hline & After 4 days & $0.643(0.393,0.893)$ & $U=48$ & $=0.080$ \\
\hline$\square$ & After 8 days & $0.560(0.405,0.716)$ & $U=82$ & $=0.039$ \\
\hline
\end{tabular}




$\begin{array}{llll}\text { After } 12 \text { days } & 0.536(0.434,0.638) & U=129 & =0.015 \\ \text { After } 16 \text { days } & 0.548(0.463,0.634) & U=177 & =0.007\end{array}$

2

3 Test statistic was used to test the significance of the difference

$4 \quad{ }^{2} P<0.05$ was considered as significantly different

5 Abbreviations: LB, lower bound; UB, upper bound; GRW, growth rate of confirmed cases in Wuhan; After 4

6 days, after the use of MSHs for 4 days; After 8 days, after the use of MSHs for 8 days; After 12 days, after the

7 use of MSHs for 12 days; After 16 days, after the use of MSHs for 16 days; Before: before the use of MSHs;

8 MCW: mortality of confirmed cases in Wuhan; GRH: growth rate of confirmed cases in Hubei; MCH: mortality

9 of confirmed cases in Hubei; MSH: mortality of severe cases in Hubei; GRNH: growth rate of confirmed cases

10 in non-Hubei regions; MCNH: mortality of confirmed cases in non-Hubei regions; MSNH: mortality of severe

11 cases in non-Hubei region; MSHs, "Fangcang, Huoshenshan, and Leishenshan" makeshift hospitals. 
Table 4 (on next page)

Tests of normality and selection of statistical methods for correlation analyses 
1 Table 4: Tests of normality and selection of statistical methods for correlation analyses

\begin{tabular}{lllll}
\hline$\square$ & \multicolumn{3}{c}{ Shapiro-Wilk } & \\
\cline { 2 - 4 } & Statistic & df & $P$ value ${ }^{1}$ & Selected statistical methods \\
\hline ATW & 0.979 & 28 & $=0.817$ & \\
GRW & 0.929 & 29 & $=0.053$ & Pearson's correlation analysis \\
MCW & 0.883 & 28 & $=0.005$ & Spearman's correlation analysis \\
ATH & 0.973 & 27 & $=0.676$ & \\
GRH & 0.944 & 28 & $=0.137$ & Pearson's correlation analysis \\
MCH & 0.882 & 27 & $=0.005$ & Spearman's correlation analysis \\
MSH & 0.863 & 27 & $=0.002$ & Spearman's correlation analysis \\
RHW & 0.838 & 29 & $<0.001$ & \\
GRW & 0.927 & 30 & $=0.042$ & Spearman's correlation analysis \\
MCW & 0.874 & 29 & $=0.003$ & Spearman's correlation analysis \\
RHH & 0.937 & 28 & $=0.094$ & \\
GRH & 0.944 & 29 & $=0.125$ & Pearson's correlation analysis \\
MCH & 0.874 & 28 & $=0.003$ & Spearman's correlation analysis \\
MSH & 0.854 & 28 & $=0.001$ & Spearman's correlation analysis \\
AQIW & 0.920 & 30 & $=0.026$ & \\
GRW & 0.906 & 30 & $=0.012$ & Spearman's correlation analysis \\
MCW & 0.866 & 30 & $=0.001$ & Spearman's correlation analysis \\
AQIH & 0.969 & 28 & $=0.551$ & \\
GRH & 0.936 & 29 & $=0.080$ & Pearson's correlation analysis \\
MCH & 0.848 & 28 & $=0.001$ & Spearman's correlation analysis \\
MSH & 0.824 & 28 & $<0.001$ & Spearman's correlation analysis \\
\hline$P>0.05$ & 0.92 & & \\
\hline
\end{tabular}

$2 P>0.05$ was considered as normally distributed

3 Abbreviations: df, degree of Freedom; ATW, air temperature in Wuhan; GRW, growth rate of confirmed cases in Wuhan; MCW, 4 mortality of confirmed cases in Wuhan; ATH, air temperature in Hubei; GRH, growth rate of confirmed cases in Hubei; MCH,

5 mortality of confirmed cases in Hubei; MSH, mortality of severe cases in Wuhan; RHW, relative humidity in Wuhan; RHH, relative

6 humidity in Hubei; AQIW, air quality index in Wuhan; AQIH, air quality index in Hubei. 


\section{Figure 1}

Comparisons of the difference in the growth rate of confirmed cases between group $A$ (16 days before the use of MSHs) and group B $(4,8,12$, or 16 days after the use of MSHs).

When the data of the two groups were both normally distributed, Student's t-test was used to compare the difference; and when the data of at least one group had a skewed distribution, Mann-Whitney $\mathrm{U}$ test was used instead. The significance of the difference between 16 days before the use of MSHs and $\mathrm{n}$ days after the use of MSHs was represented by $P_{\text {After n }}$, and $P_{\text {Attern }}$ $<0.05$ was considered statistically significant. Each box plot represents its corresponding dataset, and the bottom and top of the vertical line represent the minimum and maximum values of the dataset, respectively; the bottom and top of the box represent the first and third quartile of the dataset, respectively; and the horizontal line in the box represents the median value of the dataset. Before, 16 days before the use of MSHs; After 4, 4 days after the use of MSHs; After 8, 8 days after the use of MSHs; After 12, 12 days after the use of MSHs; After 16, 16 days after the use of MSHs; MSHs, makeshift hospitals. (A) Comparisons of the difference in the growth rate of confirmed cases in Wuhan. (B) Comparisons of the difference in the growth rate of confirmed cases in Hubei. (C) Comparisons of the difference in the growth rate of confirmed cases in non-Hubei regions. 
A

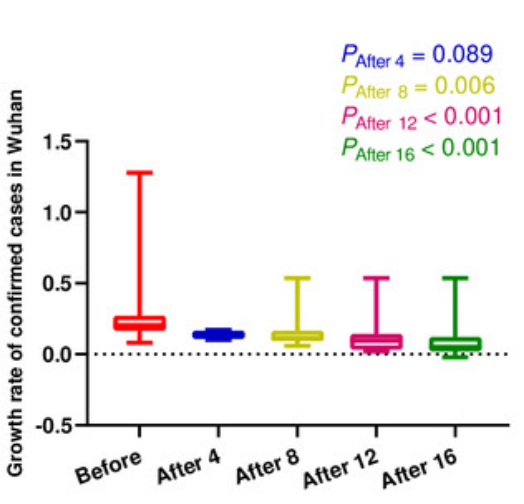

B

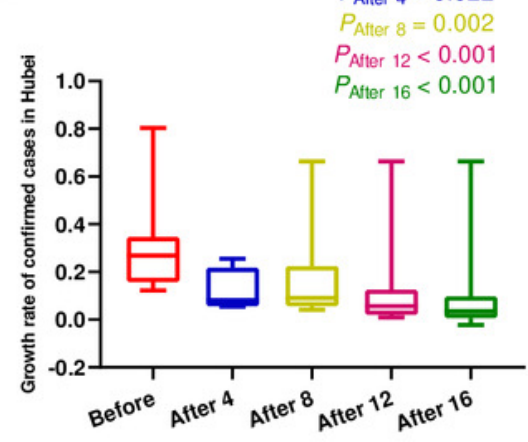

C

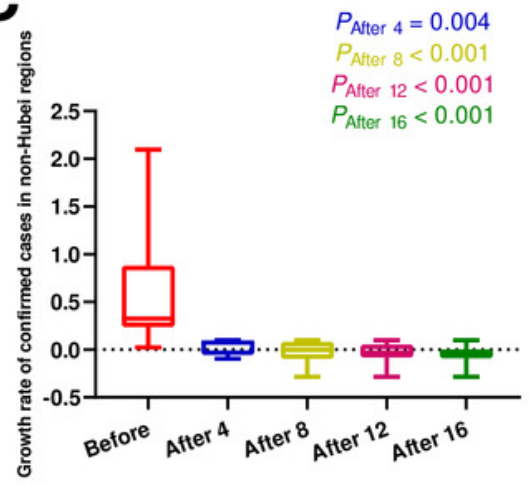




\section{Figure 2}

Comparisons of the difference in the mortality of confirmed cases between group A (16 days before the use of MSHs) and group B $(4,8,12$, or 16 days after the use of MSHs).

When the data of the two groups were both normally distributed, Student's t-test was used to compare the difference; and when the data of at least one group had a skewed distribution, Mann-Whitney $\mathrm{U}$ test was used instead. The significance of the difference between 16 days before the use of MSHs and $\mathrm{n}$ days after the use of MSHs was represented by $P_{\text {After n }}$, and $P_{\text {After n }}$ $<0.05$ was considered statistically significant. Each box plot represents its corresponding dataset, and the bottom and top of the vertical line represent the minimum and maximum values of the dataset, respectively; the bottom and top of the box represent the first and third quartile of the dataset, respectively; and the horizontal line in the box represents the median value of the dataset. Before, 16 days before the use of MSHs; After 4, 4 days after the use of MSHs; After 8, 8 days after the use of MSHs; After 12, 12 days after the use of MSHs; After 16, 16 days after the use of MSHs; MSHs, makeshift hospitals. (A) Comparisons of the difference in the mortality of confirmed cases in Wuhan. (B) Comparisons of the difference in the mortality of confirmed cases in Hubei. (C) Comparisons of the difference in the mortality of confirmed cases in non-Hubei regions.
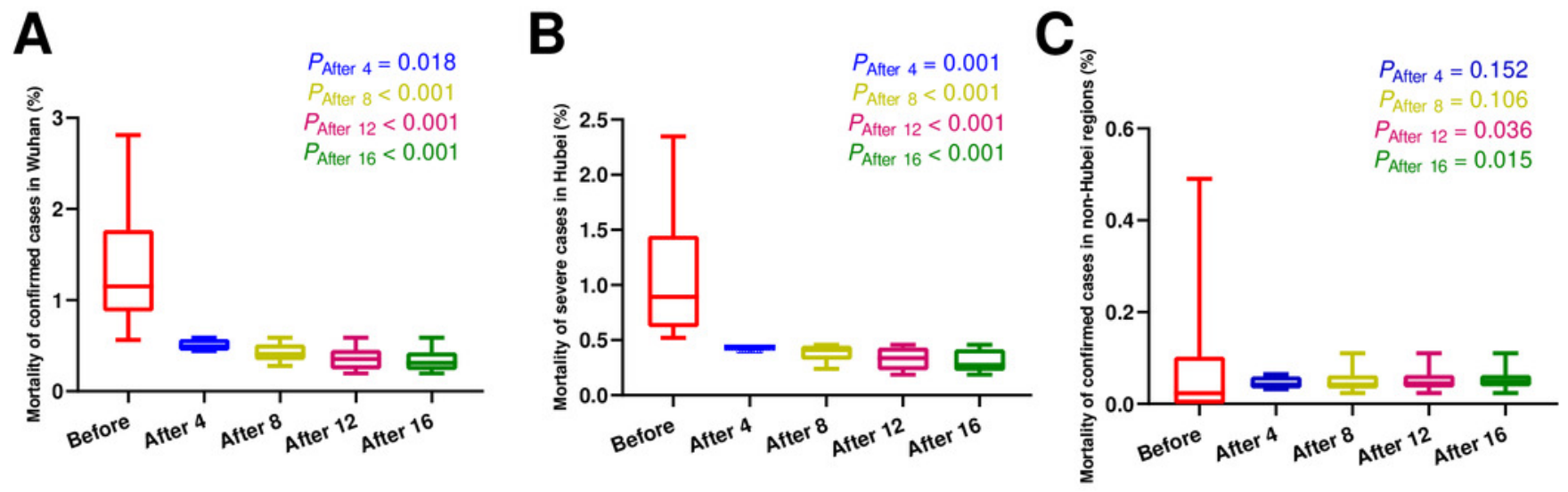


\section{Figure 3}

Comparisons of the difference in the mortality of severe cases between group $A$ (16 days before the use of MSHs) and group B $(4,8,12$, or 16 days after the use of MSHs).

When the data of the two groups were both normally distributed, Student's t-test was used to compare the difference; and when the data of at least one group had a skewed distribution, Mann-Whitney $\mathrm{U}$ test was used instead. The significance of the difference between 16 days before the use of MSHs and $\mathrm{n}$ days after the use of MSHs was represented by $P_{\text {Attern }}$, and $P_{\text {Attern }}$ $<0.05$ was considered statistically significant. Each box plot represents its corresponding dataset, and the bottom and top of the vertical line represent the minimum and maximum values of the dataset, respectively; the bottom and top of the box represent the first and third quartile of the dataset, respectively; and the horizontal line in the box represents the median value of the dataset. Before, 16 days before the use of MSHs; After 4, 4 days after the use of MSHs; After 8, 8 days after the use of MSHs; After 12, 12 days after the use of MSHs; After 16, 16 days after the use of MSHs; MSHs, makeshift hospitals. (A) Comparisons of the difference in the mortality of severe cases in Hubei. (B) Comparisons of the difference in the mortality of severe cases in non-Hubei regions. 
A

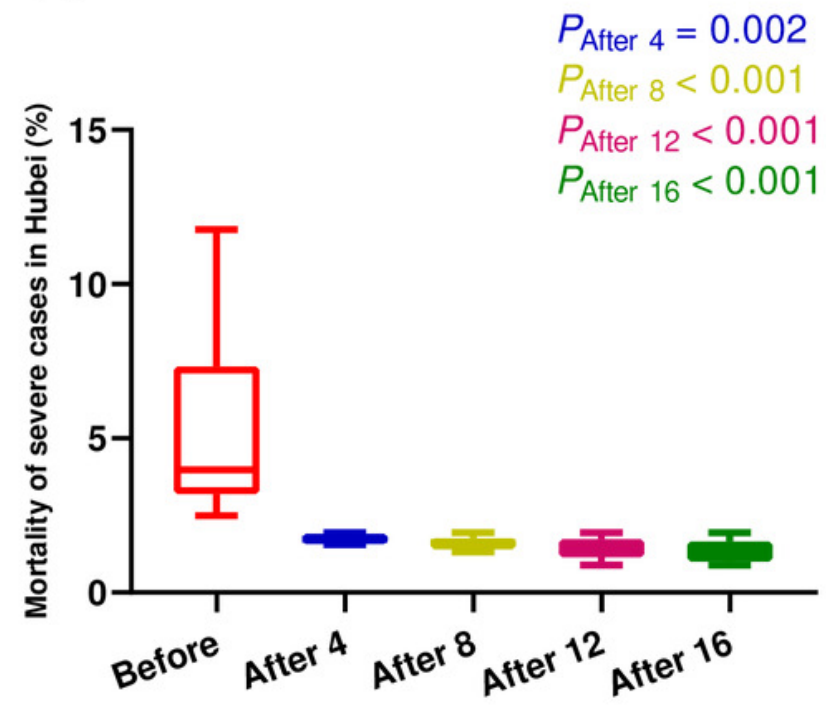

B

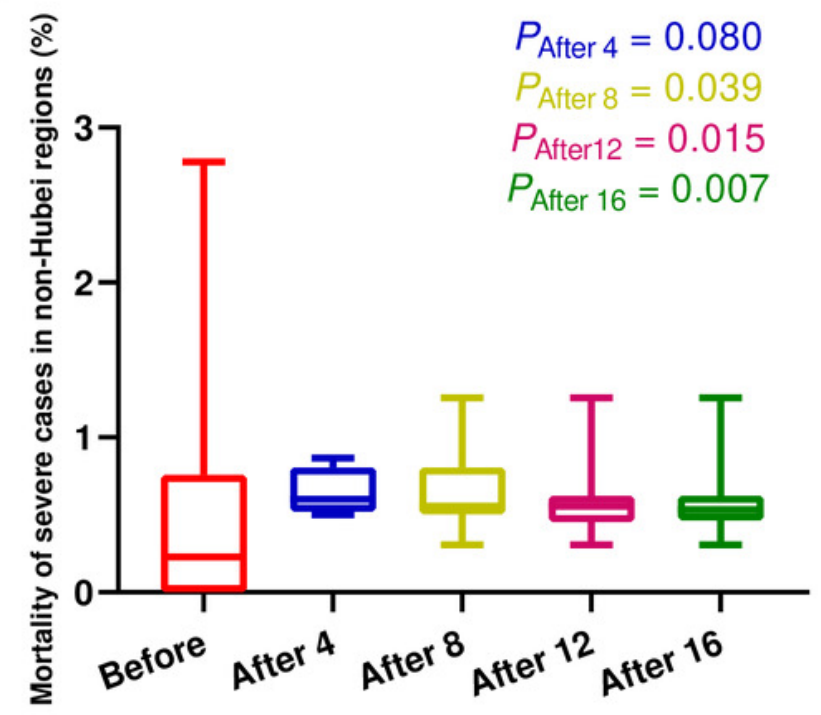




\section{Figure 4}

Correlation between air temperature and growth rate/mortality of COVID-19 cases.

When the data of the air temperature and the corresponding outcome were both normally distributed, Pearson's analysis was performed to investigate their correlation; otherwise, Spearman's analysis was performed instead. The correlation coefficient $r$ measures the strength and direction of the linear relationship between the two variables. Positive $r$ or negative $r$ represents positive correlation or negative correlation, respectively, and the closer $r$ is to +1 or -1 , the more closely the two variables are related. P-value was used to test the significance of the correlation, and $\mathrm{P}<0.05$ was considered statistically significant. (A) Correlation between air temperature and the growth rate of confirmed cases in Wuhan. (B) Correlation between air temperature and the growth rate of confirmed cases in Hubei. (C) Correlation between air temperature and the mortality of confirmed cases in Wuhan. (D) Correlation between air temperature and the mortality of confirmed cases in Hubei. (E) Correlation between air temperature and the mortality of severe cases in Hubei. 
A

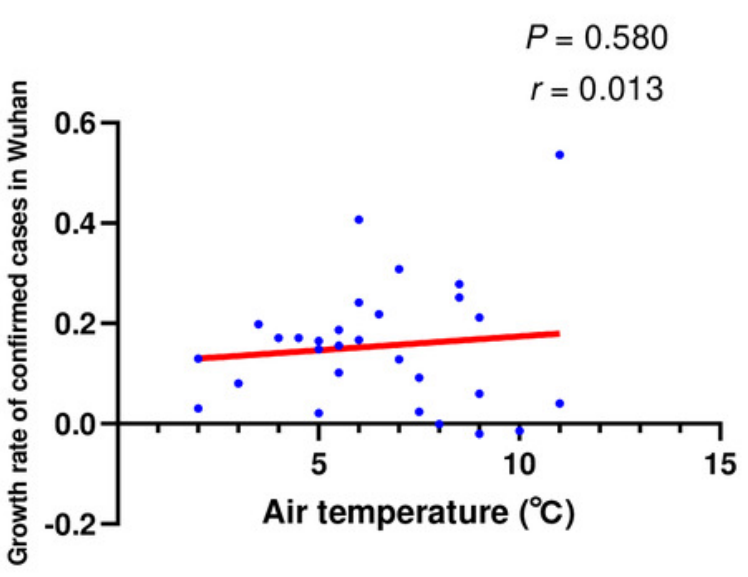

C

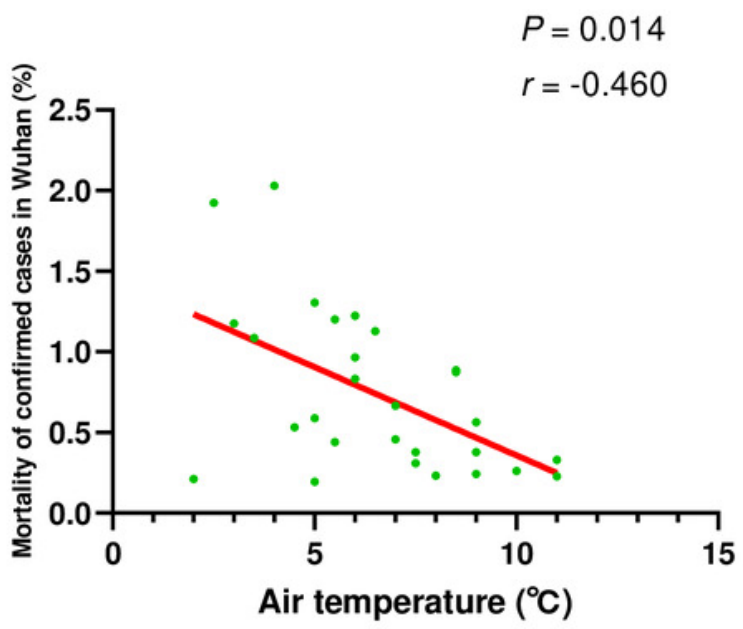

$\mathbf{E}$

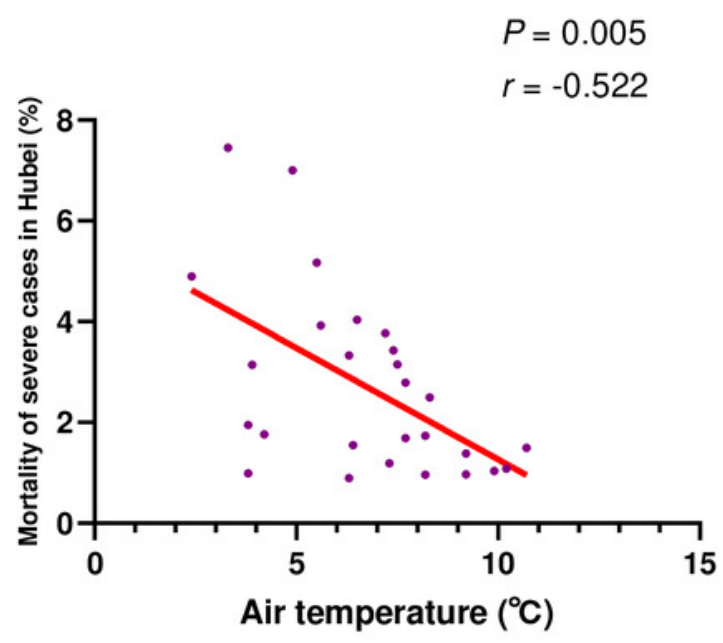

B

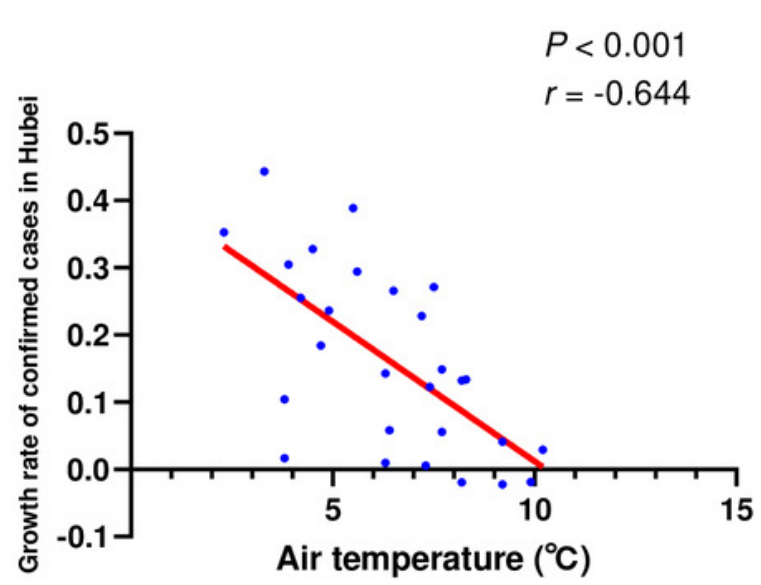

D

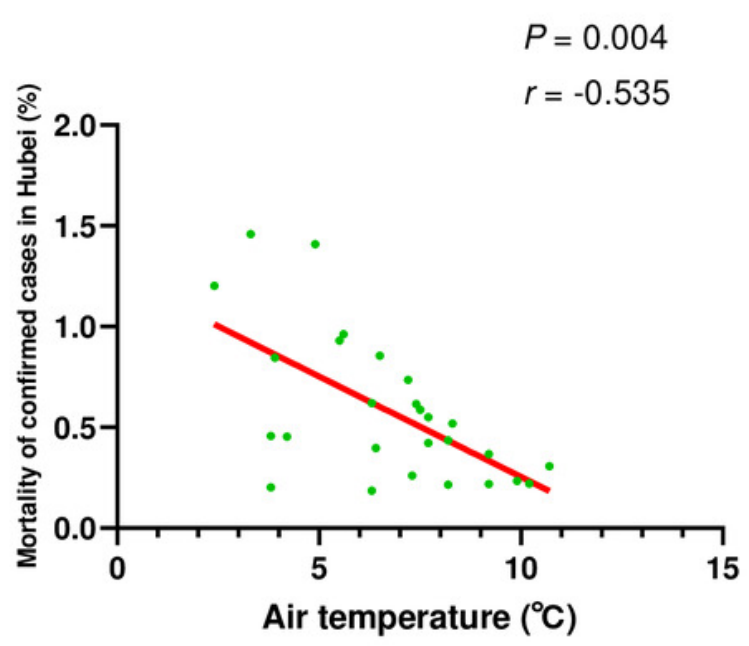




\section{Figure 5}

Correlation between relative humidity and growth rate/mortality of COVID-19 cases.

When the data of the air temperature and the corresponding outcome were both normally distributed, Pearson's analysis was performed to investigate their correlation; otherwise, Spearman's analysis was performed instead. The correlation coefficient $r$ measures the strength and direction of the linear relationship between the two variables. Positive $r$ or negative $r$ represents positive correlation or negative correlation, respectively, and the closer $r$ is to +1 or -1 , the more closely the two variables are related. P-value was used to test the significance of the correlation, and $\mathrm{P}<0.05$ was considered statistically significant. (A) Correlation between relative humidity and the growth rate of confirmed cases in Wuhan. (B) Correlation between relative humidity and the growth rate of confirmed cases in Hubei. (C) Correlation between relative humidity and the mortality of confirmed cases in Wuhan. (D) Correlation between relative humidity and the mortality of confirmed cases in Hubei. (E) Correlation between relative humidity and the mortality of severe cases in Hubei. 
A

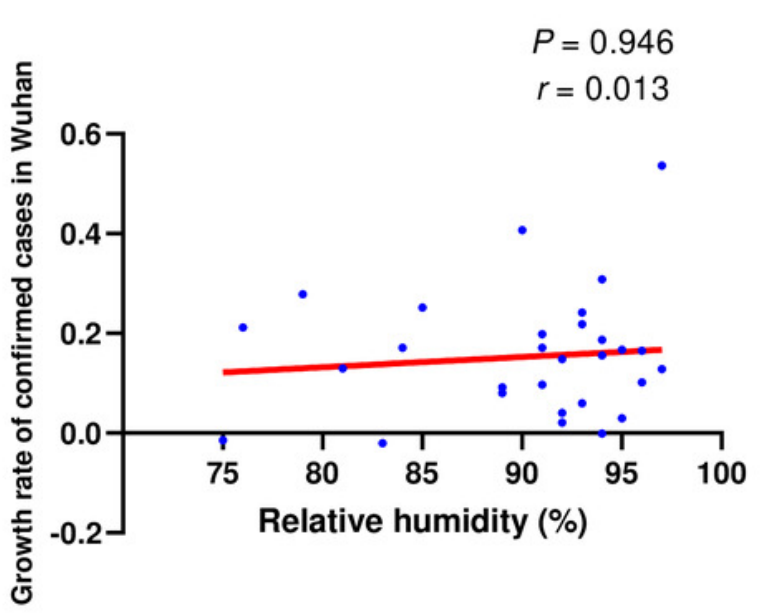

C

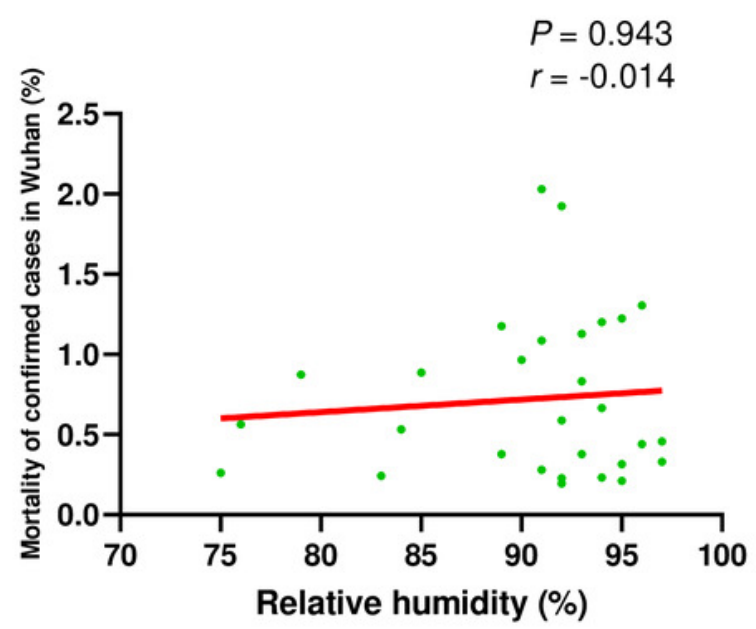

E

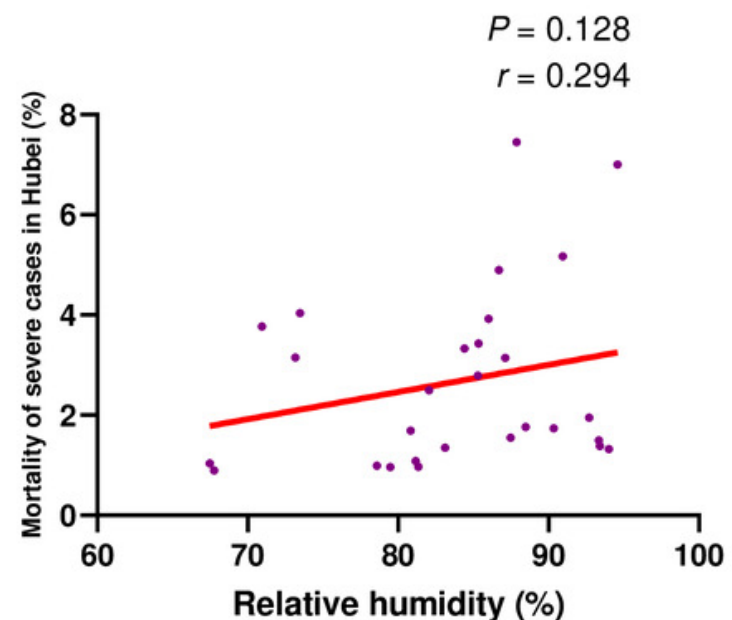

B

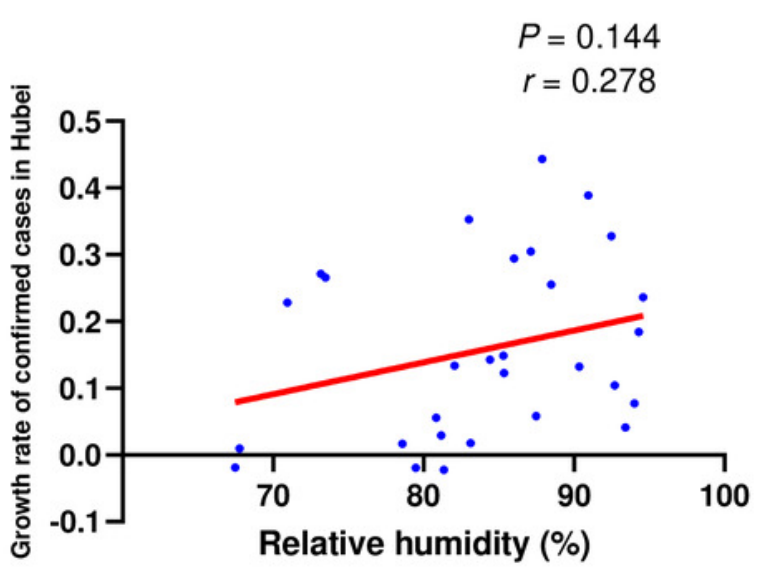

D

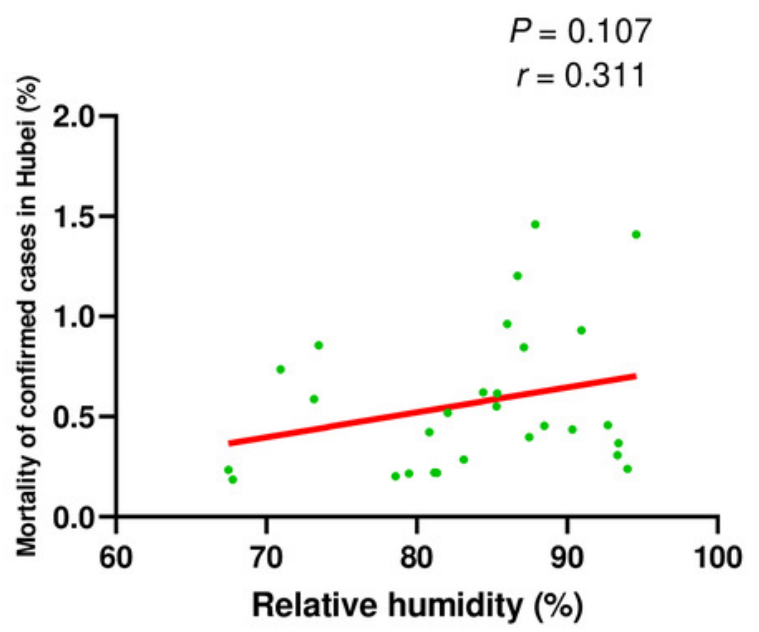




\section{Figure 6}

Correlation between air quality index and growth rate/mortality of COVID-19 cases.

When the data of the air temperature and the corresponding outcome were both normally distributed, Pearson's analysis was performed to investigate their correlation; otherwise, Spearman's analysis was performed instead. The correlation coefficient $r$ measures the strength and direction of the linear relationship between the two variables. Positive $r$ or negative $r$ represents positive correlation or negative correlation, respectively, and the closer $r$ is to +1 or -1 , the more closely the two variables are related. P-value was used to test the significance of the correlation, and $\mathrm{P}<0.05$ was considered statistically significant. (A) Correlation between air quality index and the growth rate of confirmed cases in Wuhan. (B) Correlation between air quality index and the growth rate of confirmed cases in Hubei. (C) Correlation between air quality index and the mortality of confirmed cases in Wuhan. (D) Correlation between air quality index and the mortality of confirmed cases in Hubei. (E) Correlation between air quality index and the mortality of severe cases in Hubei. 
A

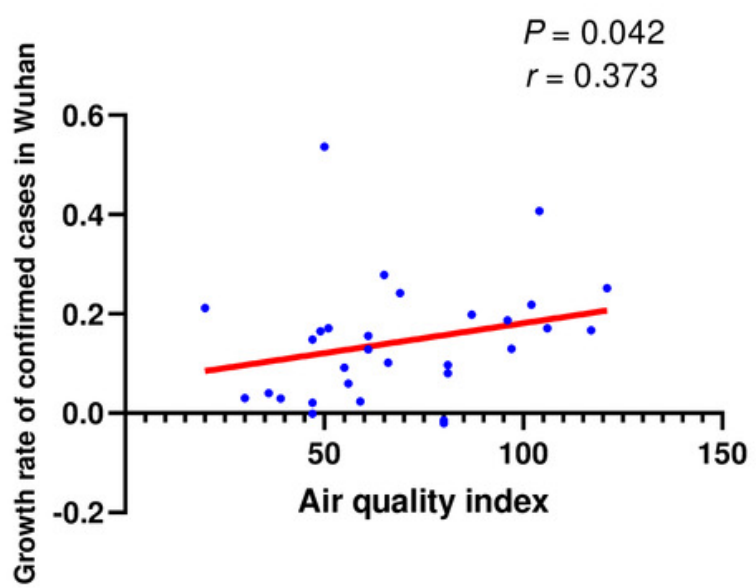

C

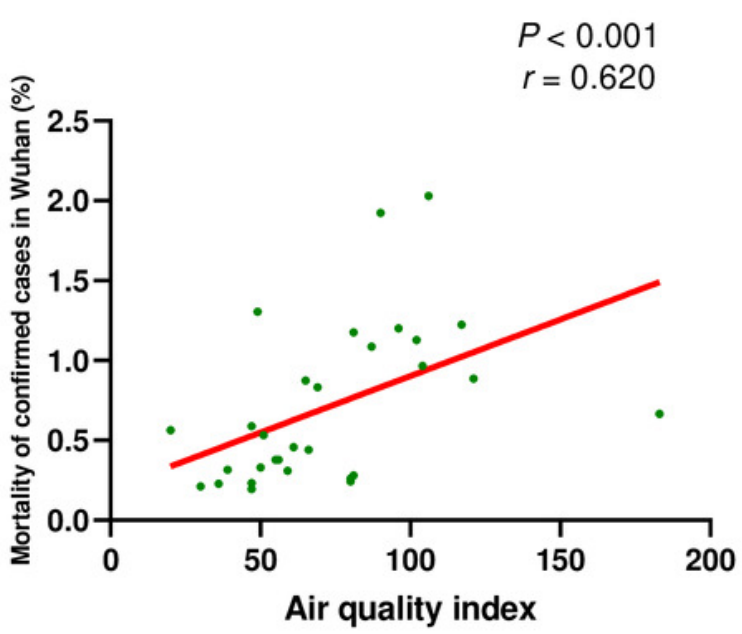

E

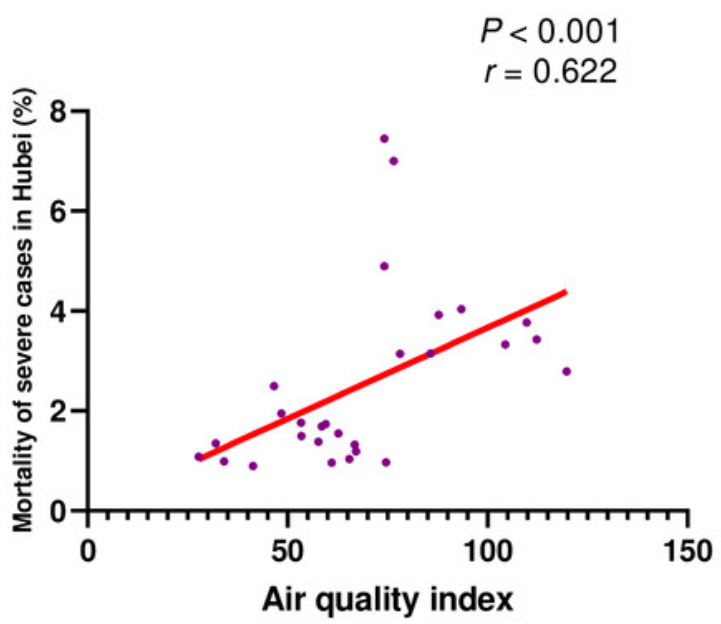

B

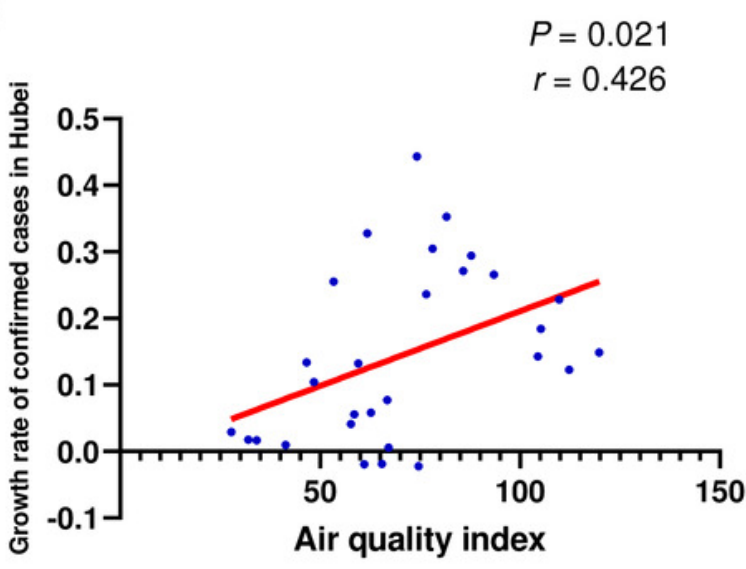

D

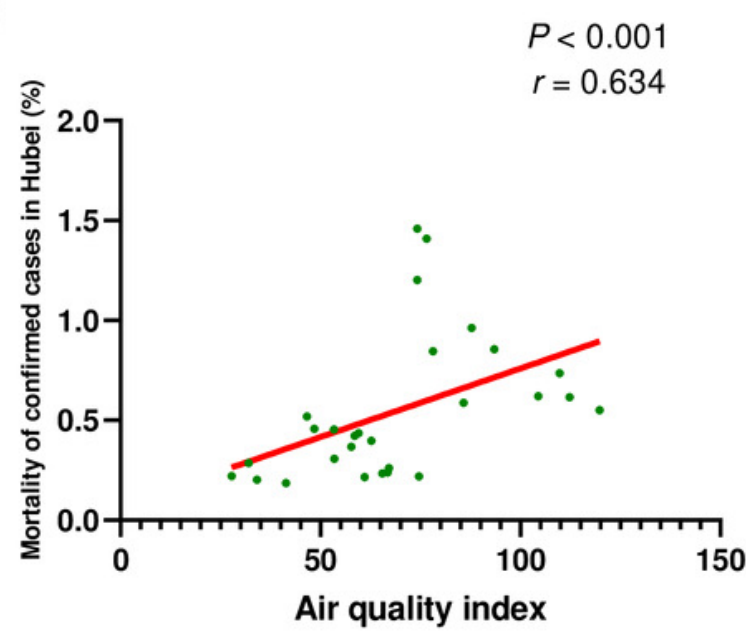

